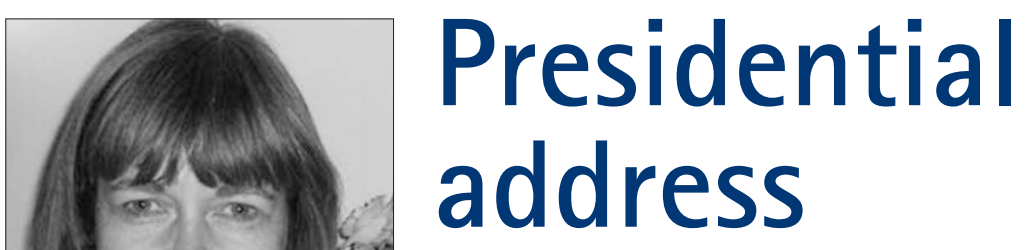

Send your comments to the

Editor-in-Chief,

British Dental Journal

64 Wimpole Street,

London

W1G 8YS

Email bdj@bda.org

Janet Clarke

Janet Clarke was installed as the new President of the British Dental Association at the 2010 British Dental Conference and

Exhibition held in Manchester on 19th-21st May 2011. The following is her presidential address.

Ladies and Gentleman, I would like to pay tribute to our outgoing President, Amarjit Gill, for all his hard work over the past year. I have known Amarjit for many years, in various different roles within the BDA. He has always struck me as being very energetic, enthusiastic and cheerful. This has been reinforced during his Presidential year, as whenever I have seen him he has told me what a marvellous time he has been having meeting members and representing the BDA here and abroad, and every photo I have seen of him in his role he has been smiling broadly. Thank you Amarjit, I am honoured to be following you as BDA President.

And what an honour; I would like to thank the members and the Association for bestowing this immense honour upon me and say how proud I am to be able to serve the BDA in this role. It has caused me not a little reflection and, Ladies and Gentlemen, I'd like to start by telling you a story. Once upon a time there was a newly qualified dentist; let's pluck a name out of thin air for her, let's call her Janet. She embarked on her career in the world outside dental school with excitement and not a little trepidation, keeping in touch with some of the other newly qualified dentists in her year to share stories and experiences. Her friends were mainly dentists who had been in her year. One day, one of these friends took her to a jazz concert (George Melly) in Hawkins Cafe Bar (a bit of an institution in Birmingham at the time). She had a good time, recognised one or two people she had trained with and even a couple of dental school tutors, and soon she realised with astonishment that the entire audience was made up of dentists; how bizarre! She chatted to quite a few people, lots of whom she hadn't met before, but felt quite at ease doing this because they all shared the same profession. At the end of the evening, she asked her friend why everyone there had been a dentist and the friend said she thought it was a BDA event and there was another one coming up soon, so why didn't they go again. Well, Janet was intrigued; she had joined the BDA as a student, of course, as it was very cheap and anyway, you had to be a member because of the Journal - that was where the jobs were advertised. She didn't realise there were meetings too but she duly went along. The next meeting was a meal in a restaurant followed by a talk from one of the dental tutors she recognised. The talk was $0 \mathrm{~K}$, but the best bit was meeting other dentists of different ages and with different experiences. Janet didn't really know a lot of people older than herself generally, but was surprised to find they had the same daily trials and tribulations that she did and were happy to offer support and advice.

Of course, the next thing that happened was that Janet was noticed attending meetings and an old BDA hand sidled up to her and suggested she should stand for 'the committee'. She was at the top of a slippery slope and off she went! First local BDA activity and then, before long, she had a letter suggesting that she might join something called the Group Management Committee at 64 Wimpole Street. This was the beginning of a journey which has culminated in this event today, because, as you will surely have guessed dear listener, that newly qualified dentist was me!

Now, I tell you that story for a reason. For a large part of my life I have been a dentist first and foremost, my friends have mostly also been dentists and I have socialised largely with dentists. However, I had two children relatively recently. My daughter nearly put in an unexpected appearance at the 2004 Bournemouth Conference: she was born eight weeks prematurely, three days after the Conference finished; I blame the hill from the Conference Hotel to the Conference Centre and the then Chief Executive's fondness for early morning breakfast briefings, which nearly killed me! Incidentally, she attended her first dental meeting at four months old and showed herself to be an aficionado by sleeping through it, waking up at the end for a drink and a nappy change! But being a parent has widened my social circle to include lots of other mothers, many of them professional women such as teachers and accountants. I have told them of my imminent Presidency and they have, to a woman, been absolutely delighted for me: 'Hey, that's amazing, great, wow!'. Then they usually add 'What's the BDA and why are you going to be President?'

It is this question which prompted the earlier story, as I have reflected long and hard about the BDA, what it means and why I have devoted quite a large part of my life to it. The BDA does many things and has many roles - scientific, educational, trade union, policy making, all of them undeniably 


\section{PRESIDENTIAL ADDRESS}

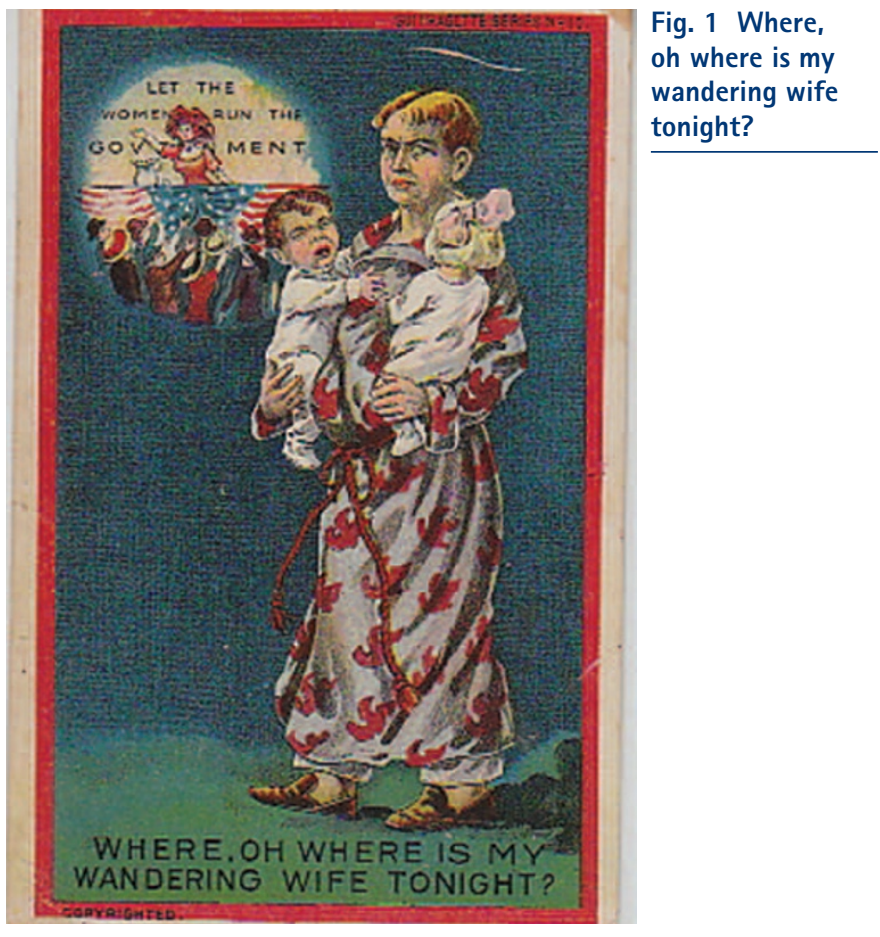

important. But I think the unique role the BDA has is that it provides opportunities for dentists from all spheres of dentistry at every stage of their career to meet and mix, share ideas, get to know each other as people and as professionals. It is so much easier to ask for clinical advice or opinion from someone you have met before and had a conversation with (even if it was about the awfulness of the coffee at a meeting) than someone who is just a name. Similarly I think you can make a more appropriate and meaningful referral if you know the person to whom you are referring and their areas of special interest. This has to improve quality of care for patients. Dentistry can be an isolated and isolating career, and we all know that professional isolation can sometimes lead to getting out of touch with changing practice and a lack of support when things go wrong. The ability to pick up the phone to a colleague you know should not be underestimated.

In addition, during my journey through the BDA I like to think I acquired some valuable skills, often by observing others. Sometimes people doing things well, sometimes less so, but always valuable experience. Skills such as chairing meetings, how to behave in meetings, speed reading and picking out salient points, how to give constructive feedback, negotiating and influencing skills. And all in an environment away from the day job, amongst professional colleagues where it felt relatively safe. I am not alone in acquiring these skills; this is one of the hidden benefits of involvement with the BDA.

These skills are eminently transferable back in the NHS. They are closely linked to clinical leadership, which I would consider to be the ability to set a direction, get other clinicians signed up to this and work with them to deliver it, by persuasion, enthusiasm and sometimes a tiny bit of coercion! The modern NHS needs clinical leaders with contacts and networks. Increasingly, as PCTs in England disappear, it will be up to local clinical leaders to set the agenda for dentistry and make sure this agenda is brought to the attention of those who need to know about it; even find out who it is that needs to know about it. Putting one's head above the parapet is sometimes uncomfortable, but a dentist who is confident in their leadership skills and has a powerful supportive local network is far less likely to get shot down! One cannot exist in the NHS nowadays without hearing the phrase Managed Clinical Network. These are being set up in different specialties in various parts of the country, as a way of improving quality of care by ensuring patients are seen by a dentist or dental care professional with the appropriate skills in the right setting, whether primary, secondary or tertiary care. They enable dentists to work together, develop their skills further and improve quality for the patient as well as job satisfaction for the dentist. I believe the BDA has an important role in equipping dentists with the skills and knowledge they need to set up and participate in the networks.

So, involvement in the BDA is definitely a two-way transaction: the BDA gets representation, meetings arranged, involvement and feedback; the BDA member who gets involved will get new friends and contacts and help in developing transferable leadership and management skills. A definite win-win situation and one we should be promoting as we move forwards to new challenges and opportunities.

I now have the privilege of being able to thank publicly those who have supported me and enabled me to enjoy working with the BDA. They are too many to mention them all by name, but I would like to single out one or two for special mention. Firstly, the staff at the BDA whom I have had the privilege of working with over the years, especially Sara Osborne, Sue Martin and Andy Williams.

Secondly, my friend and colleague Ros Hamburger; Ros has been my role model and mentor virtually since I qualified. Whenever I get into a sticky situation, I ask myself what Ros would do in such a situation and I like to think this has generally stood me in good stead.

Then the two Principal Dental Nurses, Judy Bevan and Alison Aberdeen, who run the show when I'm away (and when I'm there too, I suspect). I don't think we should underestimate the number of truly excellent dental care professionals we have and the huge impact they can have on our clinical services.

And of course, my female dental friends (they know who they are) to whom I turn when the Ros Hamburger solution hasn't quite worked out!

Finally, my husband, making a rare appearance at a BDA event today, who has held everything together at home while I have been off on BDA business. Amongst his many collections are a series of suffragette postcards (I can't imagine why!) and I wanted to share with you one of his favourites (Fig. 1). As you will see it shows a man left at home with the children wondering 'Where, oh where is my wandering wife tonight?' I would like to thank him for his patience and (mostly!) good humour.

So, I conclude by hoping you all enjoy the Conference and use every opportunity to develop further your networking skills. I look forward to meeting many of you over the next few days and the year to come. Thank you.

DOI: 10.1038/sj.bdj.2011.385 